\title{
Connection between Human and Animal Health
}

\section{Catarina Lavrador*}

Department of Veterinary Medicine, University of Évora, Portugal

*Corresponding author: Catarina Lavrador, University of Evora Department of Veterinary Medicine - University of Évora -Pólo Mitra 7000-093 Évora, Portugal, Tel: 351 266740 800; E-mail: clavrador@uevora.pt

Rec date: Oct 30, 2014; Acc date: Oct 31, 2014; Pub date: Nov 03, 2014

Copyright: ( 2014 Lavrador C. This is an open-access article distributed under the terms of the Creative Commons Attribution License, which permits unrestricted use, distribution, and reproduction in any medium, provided the original author and source are credited.

\section{Editorial}

Ever since I can remember I wanted to be a veterinarian. My mother always tells me that my fondness towards animals was such that when I was a child I even wanted to pet cockroaches. I ended up fulfilling my childhood dream and eventually became a vet. Despite loving to be a vet, mainly due to the fact that for the last fifteen years I have been strongly committed with teaching college students veterinary anesthesia and surgical techniques, my professional life always felt incomplete and somewhat meaningless. It was as if there was always a missing link to the big humane world.

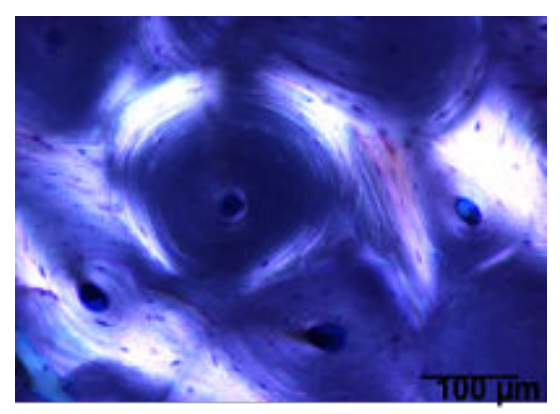

Figure 1: Sheep osteon

Attracted by its title, last year I bought a book called "Zoobiquity: The Astonishing Connection between Human and Animal Health".
This book is not only about a vast world, most of it still to be explored, but also and even more fascinating, a whole new concept of life that connects animals and humans in a vital and symbiotic way. I would dare say this book truly changed my life forever. This book gives veterinary medicine a whole new meaning by connecting it on a permanent and continuous way to the human health world. Everything from animal behaviour to indicators of cancer prognosis or cardiac conditions can be scientifically comparable. Ever since I read this book, Zoobiquity has been music to my ears and to my life. Nothing can be more rewarding than working and learning on a broader, ubiquitous level.

Being a college professor, I am now putting a strong effort on going deeper into this field of knowledge and hopefully later sharing it with my students, disclosing this hidden treasure. My goal will beto design and implement an academic course on this subject concerning this matter.

I strongly recommend this book, since it opens a new, fascinating, magic, real and especially meaningful world. Thank you Barbara Naterson-Horowitz and Kathryn Bowers, the authors. I am sure they will help us move towards a better and safer world [1].

\section{References}

1. Barbara Natterson-Horowitz, Kathryn Bowers (2013) Zoobiquity: The Astonishing Connection Between Human and Animal Health. (1stedn), Vintage, USA. 